\title{
A Natureza: Corpo e Lógos
}

\section{Nature: Body and Logos \\ PAULO ROBERTO DE OLIVEIRA}

Resumo: A ideia de natureza assume uma relevância peculiar na tradição filosófica. O artigo visa retratar, mediante o confronto entre Merleau-Ponty e Sartre, a complexidade ontológica do tema. Para tanto, o ponto central aqui consiste em descrever a experiência da corporeidade como sistema ontológico cultural e natural em direção a uma compreensão da noção de natureza como "via para a própria ontologia".

Palavras-chave: Corpo. Fenomenologia. Ontologia. Natureza. Sensação.

Abstract: The idea of nature is of particular relevance in philosophical tradition. This article aims to portray, by means the confrontation between Sartre and Merleau-Ponty, the ontological complexity of the theme. Thus, the point here is to describe the experience of corporeality as a cultural and natural ontological system toward an understanding of the concept of nature as a "path to own ontology".

Keywords: Body. Phenomenology. Ontology. Nature. Sensation.

\section{Introdução}

A ideia de corpo no contexto da filosofia da natureza de MerleauPonty assume importância singular. $\mathrm{O}$ pensamento e a liberdade se dão na medida em que existe um corpo: "a encarnação do espírito" retrata o filósofo - "levava a recusar a presença a si do pensamento" (MERLEAU-PONTY, 20oo, p. xiv). Desse modo, a situação não é um limite à liberdade, mas sua própria condição.

Ora, Merleau-Ponty compreende que a ideia de natureza é tão 
complexa quanto a ideia de Deus. Dessa maneira, a filosofia da natureza e a teologia são duas faces de uma mesma moeda: ambas pretendem fixar uma fundamentação para o ser. Ao longo de sua obra, Merleau-Ponty destaca essa tentativa, sobretudo, através do mecanicismo de Descartes e o idealismo de Hegel. Merleau-Ponty ainda parte de um ponto importante no desenvolvimento de sua ideia sobre a natureza: o corpo e a consciência são experiências homogêneas, inexistindo qualquer relação causal entre ambos. Para tanto, o filósofo emprega o método fenomenológico visando descrever a passagem do mundo percebido para o mundo do conhecimento, via uma teoria da verdade e da intersubjetividade. A linguagem simbólica representa a história da humanidade, o mundo cultural. Essa se faz pela comunicação, isto é, pelos outros, uma vez que não existe pensamento monológico.

Tal concepção abre caminho para uma nova ontologia. Dessa forma, em A Natureza, Merleau-Ponty tem a pretensão de estender, em profundidade, o campo da fenomenologia, bem como, extrair da natureza concebida como "o outro lado do homem", quer dizer, uma análise do corpo como entrelaçamento da natureza e da linguagem como expressão simbólica. Trata-se de fundar, filosoficamente, uma história da humanidade em sua unidade. É, pois, uma nova ontologia que assim torna-se possível.

Sabemos que uma interpretação filosófica da ideia de natureza carece de um método ontológico mais profundo, pois, a ideia de natureza do senso comum está relacionada com as ciências naturais, isto é, a biologia, a astronomia, a física, a química e a teologia. $\mathrm{O}$ trabalho do filósofo da natureza consiste em fundamentar a ideia de natureza levando em conta a própria ideia de racionalidade. Qual é a 
racionalidade da ideia de natureza? É possível conhecê-la?

\section{Natureza e Cultura}

Para Merleau-Ponty, a "nova ciência" (contemporânea) foi a grande responsável por articular a ideia da natureza, noutro patamar. Até então, tal concepção era construída pela relação ontológica judaico-cristã, fundamentada pelo cartesianismo. Na metafísica clássica há uma duração na natureza que a torna mecânica, estática e divina. É por isso que Descartes entende a natureza como sendo o próprio Deus. Merleau-Ponty mostra que tal concepção desenvolveuse de duas maneiras diferentes: há, em Descartes, uma "ontologia do objeto" ou uma "ontologia do existente".

$\mathrm{Na}$ ontologia do objeto, encontramos, a partir da base da reflexão filosófica, a tese da durabilidade natural:

Na base de uma ontologia objetiva está a convicção de que o trabalho do filósofo, refletindo sobre o ser, consiste em realizar uma depuração do contato imediato que temos com o ser, para discernir o que é sólido, o que resiste ao entendimento. A natureza exterior reduz-se então, segundo Descartes, à extensão. A extensão possui duas características: ela é indefinidamente divisível e, na medida em que podemos falar de pontos de extensão, cumpre considerá-los como não substituíveis reciprocamente, ou seja, tendo cada um sua localidade própria. Cada parte não é outra coisa senão a sua alteridade em relação às outras. Daí resulta que cada parte é plenitude de ser. Com efeito, não sendo cada ponto senão a sua alteridade, a extensão é a mesma em todos os pontos, sem céus nem relevo. A extensão é por toda parte igualmente plena, porque é igualmente vazia. Ela só é o que ela é. 
Por isso, o mundo exterior será inteiramente atual: não há lugar para uma diferença entre os seres atuais e os seres possíveis nem para uma reminiscência do passado ou uma antecipação do futuro (MERLEAUPONTY, 2000, p. 204).

A essencialidade dessa filosofia natural de Descartes consiste em afirmar a existência de leis que residem na estrutura da criação do mundo; daí segue-se a necessidade da extensão. O ser do objeto é marcado pela essencialidade absoluta do mundo em que, no vazio da existência, não há lugar para o possível.

Ora, a essência do mundo não se esgota pela aparição da extensão. A extensão é infinita, mas, acrescenta Descartes, infinita enquanto extensão. Só Deus pode ser apresentado como o objeto verdadeiramente objeto. Vimos anteriormente que a extensão é sólida e, por isso mesmo, resistente ao entendimento. Nas Meditações Metafísicas, porém, enquanto existência que revela o verdadeiro ente infinito Deus está no nível do pensamento articulado. A ideia divina é um pensamento a priori. Por outro lado, a natureza, como extensão, só pode ser conhecida, a posteriori, e de uma forma objetiva.

Sartre afirma a partir de uma teologia negativa (ou teologia do absurdo) que a ideia de natureza, isto é, o próprio mundo significa, mesmo considerando que Deus exista, uma total ruptura com esse ente divino. Na filosofia clássica de Plotino, o mundo emana de Deus, o uno existe no múltiplo. Eis, portanto um grande problema filosófico: como explicar o uno se só temos em vista o múltiplo? Para Descartes, embora represente uma ruptura com a existência de Deus, a natureza é consequência do aparecimento ilimitado do próprio Deus.

Nesse caso, ao realizar uma retrospectiva criadora, Descartes prediz a plenitude do ser que está por trás da natureza. Tal plenitude é 
representada pelo poder criador que contém tudo aquilo que pode aparecer.

Aquilo que aparece está sujeito a um entendimento. A filosofia do entendimento é, na verdade, a ideia de um pensamento ilimitado e livre que conduz à própria existência, a um sentido de ser. $\mathrm{O}$ pensamento não coloca nenhuma necessidade nas coisas; no entanto, para dizer o que uma coisa é, nos remetemos ao pensamento. Tal processo intelectivo não é nada mais que colocar uma lei necessária na coisa e, desse modo, há uma necessidade intrínseca ao aparecimento da coisa. Descartes não nega que a solidez do mundo implica uma distância entre o pensamento e a coisa, porém, as coisas dependem do pensamento, pois, a verdade está na ideia. A grande tarefa fracassada da filosofia foi tentar mostrar que as coisas são, e o nada, nada é mais que é um estrabismo que surge da dúvida. O argumento do "cogito" cartesiano além de afirmar a existência ontológica do mundo e de Deus, funda uma necessidade no sujeito pensante: "para pensar é preciso ser".

Merleau-Ponty nota que o interesse cartesiano com o nada acaba revelando uma existência desse processo de nadificação, pelo qual surge o ser, isto é, a própria criação ex-nihilo, expressando o poder do nada. Desse modo, a ontologia do existente se articula a partir dessa díade: ser e nada. Pois bem: na filosofia contemporânea, a ideia do ser absoluto, enquanto liberdade sem limites é nada mais que uma projeção do espírito humano.

A ideia de infinito não tem que vir de outro lugar que nós mesmos, de nossa liberdade sem limites, e é a partir dessa liberdade que nós transferimos a ideia para as coisas (MERLEAU-PONTY, 2000, p. 207). 
A liberdade necessária tem sua representação maior no Esse Divino. O sim do Deus infinito é um sim absoluto. Segundo Vaz, tratase de uma ideia que se encontra desde Plotino:

Em seguida, Plotino dedica-se a uma reflexão altamente especulativa sobre a absoluta transcendência do Uno-Bem e sobre os predicados que convém atribuir-lhe. Finalmente, designa o UnoBem como Vontade e Liberdade absolutas, pois somente Ele é Ele mesmo (autos auto) ao passo que tudo mais é o mesmo e outro. Toda alteridade é, portanto, excluída da liberdade absoluta enquanto idêntica ao bem (VAZ, 2008, p. 119).

A grande pergunta da revelação é: "O que sou”? A resposta compreende um essencialismo típico. "Sou o que sou", isto é, existência plena de ser. $\mathrm{O}$ existencialismo é a mancha no ser. O que é que eu sou? Essa resposta, se procurada na interioridade da existência, depara-se com o nada. O que eu sou está sempre adiante, longe do meu próprio ser. Desse modo, enquanto a "ontologia do objeto" se dá mediante a natureza objetiva (extensão) e, por isso mesmo, o pensamento que se debruça sobre essa realidade objetiva é sempre limitada, por outro lado, a “ontologia do existente" é o pensamento puro sobre o ser, sobretudo, o Ser de Deus.

Para Merleau-Ponty existe uma relação ínfima entre esses dois modos de pensamento: Primeiro: nos dois casos a razão aparece como senhora de nossas afirmações. Segundo: Deus é incompreensível; não é incognoscibilidade e nem irracionalidade, mas, a razão formal do infinito. A compreensão total de Deus seria a sua própria destruição. Terceiro: o pensar do homem se identifica com o pensar de Deus. Nesse último ponto encontramos alguns problemas. A princípio, podese considerar que a relação homem-Deus é simples, pelo fato de que é 
na minha liberdade que descubro o infinito. Por outro lado, também podemos dizer que essa relação não é simples, porque o homem não é uma coisa criada, mas um espírito. Ora, para Descartes, não podemos pensar em um finalismo, mas numa natureza mecânica e ordenada por Deus. Como já vimos, pensar a totalidade de Deus é impossível:

Devemos apenas dizer somente que Deus existe. Não podemos pensar nem a ação de Deus, nem a vida, exceto por analogia. Em suma, chegaríamos numa espécie de fato total do mundo, que seria também o fato de Deus, mas fato total que não podemos julgar, por não ter poder para dominá-lo (MERLEAUPONTY, 2000, p. 209).

$\mathrm{O}$ pensamento ocidental judaico-cristão possui as mesmas oscilações do pensamento cartesiano. Tais oscilações estão na base da diferença epistemológica existente entre natureza e cultura. Segundo Merleau-Ponty, existem três maneiras de pensar o ser e, por conseguinte, pensar Deus, a natureza e o homem:

Um primeiro pensamento da natureza mecanizada vincula a natureza a uma necessidade a tergo, e a qual corresponde uma ideia de Deus como essência e como entendimento, assim como uma ideia do homem como mistura de ser e de nada, isto é, como sombra. Tal pensamento retrospectivo refere-se sempre a um outro ser, que as aparências só parcialmente revelam. Em segundo lugar, um pensamento prospectivo, que admite uma natureza finalizada, um Deus como vontade e um homem como realidade, e que é atestado pela existência e um elo entre a alma e o corpo. Finalmente, um esforço para ir mais além, colocando-se no nível de Deus, que se situa aquém dos possíveis e de quem não podemos dizer nem que é necessário nem que o que 
ele faz é contingente. Deus é, então incompreensível e só será apreendido a partir do mundo, mundo que se auto definirá como indiferente (MERLEAUPONTY, 2000, p. 214).

Existe, aqui, um ponto crítico crucial. Tomás de Aquino, seguindo a tradição teológica, afirma a totalidade do ente divino: Deus é também o único ser ou o ser, por excelência. Portanto, a tradição cristã antecipa o princípio niilista do existencialismo. Porém, o pensamento humano é essencialmente ontológico: todas as outras formas de pensar são subordinadas a essa estrutura fundamental, tanto o naturalismo quanto o humanismo.

\section{O Naturalismo}

A estreita relação existente entre ontologia e naturalismo é, de certo modo, aparente. Em Laplace, a natureza toma o lugar de Deus. A natureza física é um fato único, uma grande verdade. Segundo Merleau-Ponty, essa única Verdade existe como tal, diante de um espectador. Esse espectador é, para Laplace, o espírito do cientista.

Já, no naturalismo romântico de Schelling, a relação homemnatureza é de ordem recíproca. Em Marx, por exemplo, a natureza significa um humanismo perfeito. O homem através do trabalho transforma a Natureza em antiphysis. Tal concepção se encontra também nos manuais antropológicos e culturais do século XIX: existe uma ruptura entre o homem e a natureza, efetivado pelo trabalho. De modo rudimentar, conjeturamos um mundo cultural avesso à natureza, ou seja, o que é próprio do ser humano e o que é natural. Para definir o objeto humano deve-se realizar uma ontologia, isto é, o que conta não é definir o papel da natureza, mas colocar o problema ontológico, ou seja, o problema da relação entre o objeto e o sujeito. A 
história do pensamento não nos deixa enganar sobre o fato de que, na verdade, o naturalismo é uma forma de humanismo; assim, também, acontece com a teologia. Feuerbach e Marx conseguiram demonstrar a psicologia existencial presente na religião e na natureza. A dialética marxista é, acima de tudo, uma dialética natural.

\section{O Humanismo}

A antropologia filosófica tem um princípio que, por vezes, parece próprio da filosofia da linguagem de Wittgenstein: "tudo aquilo de que podemos falar é um atributo do homem”. Segundo Merleau-Ponty, existem três formas de humanismo: i) Humanismo criticista, ou seja, como o sujeito faz parte do universo? A filosofia idealista converte-se em filosofia finalista, as relações entre diferentes sujeitos e as relações com um mundo exigindo a finalidade. A busca pelo fim identifica-se com a busca pelo ser. Há, ainda, ii) o Humanismo sartriano: o homem é o lugar de uma dupla relação entre o ser e o nada. Existe iii) o humanismo heideggeriano: humanismo no sentido em que o homem é definido como "pastor do ser", aquele que deixa ser as coisas. O homem é abertura, não é realidade plena. A questão é que o humanismo ganha enorme repercussão na filosofia do século XX. Ao contrário do antropocentrismo, o humanismo caracteriza o homem do modo como ele é, sem colocar véus ou ilusões metafísicas. De todo modo, o humanismo situa-se no plano ético, existencial, ontológico e natural.

O ateísmo, por exemplo, de Sartre, é uma das mais importantes formas de humanismo: se Deus existe o homem não é, se o homem existe Deus não é. Em certo sentido, estabelecer Deus como ser é operar uma negação do mundo: é dizer que o resto não é. Só é na 
medida em que participa do ser de Deus. Na religião existe uma ligação Deus-Homem que se estabelece pela analogia do "Arquiteto com a obra”, na qual, os homens se sacrificam para unir-se a Deus.

Enfim, após essa escalada acerca da humanização da natureza e do mundo, uma questão emergente se põe: como o homem pode simbolizar a natureza sem cair em um humanismo idealista? De certo, esquecemos-nos de um elemento tão humano quanto a cultura: o corpo. Em Merleau-Ponty, a relação entre natureza e logos se efetua pela ideia de corporeidade enquanto conceito-chave para a questão da natureza.

\section{Corporeidade e Existência}

\subsection{Corporeidade e Comportamento}

Na penúltima parte de A Natureza, Merleau-Ponty analisa a animalidade para realizar uma comparação sintética com o corpo humano e a ideia de logos. No início dessa descrição, o filósofo elenca as tendências da biologia moderna. Entretanto, algumas questões permanecem: materialismo ou vitalismo, inato ou adquirido, maturação e aprendizagem. Faz-se necessário um estudo puro do comportamento, pois, mesmo com o sentido mental, o comportamento está ligado à ideia de corpo. Ora, essa concepção só é possível a partir do momento em que o corpo deixa de ser uma máquina. Desse modo, se o organismo não é uma máquina, então o comportamento converte-se numa realidade quase orgânica. Existe um princípio de totalidade; as reações locais estão envolvidas estreitamente no comportamento total. Há também uma maturação biológica. Tal feito se realiza de forma benéfica, pois as fases da organização biológica esboçam as tarefas que o organismo tem a 
cumprir. O comportamento inicial do animal é organizado sob gradientes pré-neurais; o sistema nervoso emerge a partir de uma dinâmica pré-neural. O sistema nervoso não é, pois, a explicação última. Se os animais vertebrados superiores têm, diferentemente dos insetos, uma enorme capacidade de aprendizagem é porque os tecidos nervosos estão envoltos numa matriz de tecidos embrionários. Essa matriz deve ser depositária de uma potencialidade de crescimento e o neurônio deve continuar a crescer, uma vez em funcionamento, e isso de maneira puramente embrionária. Coghill quer mostrar que, se o comportamento é um enigma para uma anatomia estática, é porque ele só pode ser compreendido por uma anatomia dinâmica. Toda a estrutura corporal significa a vasta possibilidade de comportamento. Segundo Coghill, a maturação do organismo e o surgimento do comportamento constituem um só fenômeno. Tal comportamento representa um poder de corpo animal sobre o mundo exterior (Cf. MERLEAU-PONTY, 2000, p. 235-236).

Para Merleau-Ponty, o corpo é um esboço do comportamento. O desenvolvimento embrionário antecipa o comportamento futuro, os órgãos ou esboços do embrião não têm o menor sentido se os consideramos independentemente de toda a lógica do comportamento. O organismo é sinônimo de comportamentos possíveis no futuro. Neste caso, o corpo é um sistema de potências motoras que se entrecruzam para produzir um comportamento.

Nessa perspectiva, Merleau-Ponty elabora sete princípios da morfologia dinâmica: 1) existência de antecedentes no desenvolvimento embrionário; 2) todo desenvolvimento é orientado; 3) desenvolvimento do organismo em espiral por reincorporação de condutas inferiores em um nível superior; 4) princípio de 
entrelaçamento recíproco; 5) princípio de assimetria (ausência de simetria); 6) princípio de "flutuação auto-reguladora" e, por fim, 7) todo comportamento tende para certo ótimo (princípio de tendência ótima) (Cf. Idem, op. cit., p. 242-243). Novamente a partir desses princípios acima, se prova que o corpo não é uma máquina. Além dessas, Merleau-Ponty elabora duas outras razões:

Não existe uma distinção clara entre o combustível e a máquina: o organismo queima sua própria substância e reconstrói por retirada antecipada da substância combustível. $\mathrm{O}$ organismo não é uma máquina, mas um estado de grande dinamismo (Idem, op. cit., p. 244245). Afora isso, o comportamento não desce no organismo como uma visitação vindo do alto. Ele emerge, antes, dos níveis inferiores (Idem, op. cit., p. 244-245).

Segundo Merleau-Ponty, a psicologia é capaz de aceitar e compreender a totalidade corpo/comportamento. Para tanto, utilizase do método fenomenológico que, a partir da percepção minuciosa, é capaz de nos revelar aquilo que vemos. Neste caso, o todo pode ser a soma das partes sem ser uma realidade transcendente. O pensamento clássico pensa a totalidade como ente divino. $\mathrm{O}$ todo se representa a partir do fenômeno nas partes. É, portanto, um princípio existencial. Não há distinção entre ato e potência, tudo está em ato.

\subsection{A ideia de Corpo}

Antes de tudo, devemos colocar uma questão já antecipada por Merleau-Ponty: qual o estatuto do corpo no estudo da natureza? A evolução tem um sentido existencial profundo: é uma transição da natureza para o homo sapiens. Vimos até instituições animais (o amor dos animais), uma plasticidade, a qual não é sempre medida pela 
inteligência animal. Reciprocamente, o homem não é animalidade (no sentido mecânico) + razão - E é por isso que nos ocupamos de seu corpo: antes de ser razão, a humanidade é outra corporeidade.

Merleau-Ponty realiza três esboços sobre o corpo. No primeiro esboço, o corpo é relação, movimento e percepção. Não é, pois, uma coisa, mas um Welt. A questão enigmática se encontra na teoria da carne: como pode a carne suscitar um espírito? Diz ele: a estrutura do corpo como carne é libidinal. Um espírito não desejaria, o Eu do desejo é o corpo. O corpo é algo aberto que recebe os seres do mundo. Ele é massa de prazeres e de dores, que não estão fechados sobre si mesmos. Há também no corpo um simbolismo: no corpo há um lógos estético, no qual se apoia o logos da linguagem. A problemática da filosofia que coloca a natureza ontológica. Por isso se faz necessário abordar o homem primeiramente em seu corpo (Cf. MERLEAUPONTY, 2000, p. 337-348).

No segundo esboço, Merleau-Ponty retrata, no corpo animal, a relação com um Welt circunscrito. Entretanto, o corpo humano é habitado por uma consciência: "Sou testemunho do meu Umwelt". (Umwelt+consciência+corpo). É por meio do meu corpo que estou dentro do mundo, e sou aberto a ele. A matéria corpórea é o Gênesis da vida. O nascimento: a alma da criança não é proveniente da alma da mãe, não existe gravidez da alma. É um corpo que produz a gravidez e que passa a perceber quando as ações do mundo o atingem. Não existe alma descendo num corpo, mas, antes o surgimento de uma vida em seu berço. É o corpo que vê como totalidade aberta, não é a alma e nem o olho. O sensível é a carne do mundo, isto é, o sentido do exterior. A carne do corpo é a cerne do mundo, pois a percepção do mundo está na nossa carne. O corpo libidinal e a intercorporeidade: o 
desejo ocorre pela finitude do próprio ser-para-si. Ora, na psicanálise existencial, tal qual Sartre a entende, o objeto do desejo não é substancial, pois carece de sentido pleno. É a falta de ser que determina a busca pelo ser. Na concepção merleau-pontyana, as coisas são aquilo que falta ao meu corpo para fechar o circuito. Há o nível de uma teoria do reconhecimento: através do meu corpo conheço o outro e ocorre também o reconhecimento, pois meu corpo é feito da mesma corporeidade dele. Os outros me aparecem como fisionomias. Disso deriva, a relação entre corpo e simbolismo: a linguagem é uma retomada do logos corpóreo. Para além da linguagem visível, há continuidade da comunicação pelo invisível. Aos olhos de MerleauPonty, o final desse programa é uma disputa do próprio ego: o ser bruto ou selvagem contra o ser sedimentado - ôntico. Inicia-se um processo na definição do ser pelo interior (Cf. Idem, op. cit., p.p. 348354).

No terceiro esboço, o corpo é uma coisa sensível, mas cujos movimentos formam por si um sistema no simultâneo e no sucessivo não apenas uma massa individual - mas uma massa articulada, um sistema diacrítico. Esse sistema é a pedra angular do mundo ou, inversamente, tem sua pedra angular no mundo e abre para o mundo. Daí melhor se compreende a relação entre corpo libidinal e a intercorporeidade: nesse ponto, Merleau-Ponty parte do princípio da estesiologia: há uma unidade forte entre a alma e o corpo. Quer dizer: esse corpo como carne está em meio às coisas. Enquanto postura no mundo é capaz de expressar um ponto de vista sobre as coisas. $\mathrm{O}$ corpo exige algo além do corpo - coisa ou das relações consigo mesmo (sentir-se homem pelo espírito e pela carne). O prazer busca a realidade de forma obcecada. 
Com isso, o corpo humano está repleto de simbolismo. Na verdade, o visível e o invisível são duas faces da mesma moeda. A idealidade que pode se articular pelo simbolismo é um mundo a se fazer, contudo, o real é pleno de sentido (Cf. Idem, op. cit., p. 354-367). Quando se fala em ontogênese pretende-se esclarecer que o primeiro geneticamente não é o primeiro transcendental. O princípio da realidade é a eliminação dos possíveis que não fazem parte da totalidade. A estesiologia nos remete a uma teoria da não objetividade de maneira que a coisa é não definível sem predicados perceptivos. $\mathrm{O}$ percebido não está em mim. O mundo é tomado no percebido.

No corpo libidinal, a sensorialidade implica, intencionalmente, a incorporação, isto é, um funcionamento do corpo como passagem para um exterior, por seus orifícios. Portanto, há indivisão do meu corpo, de meu corpo e do mundo, do meu corpo e dos outros corpos, e dos outros corpos em si. A sensorialidade é um investimento: imobilização de um poder a serviço de ... E investimento na promiscuidade dos poderes, dos poderes e dos outros e dos outros entre eles. Assim sendo, a corporeidade como relação com as coisas e com os outros vai comportar toda sorte de fórmulas segundo a estruturação do esquema corporal: as fases de Freud, por exemplo, são estruturações desse gênero. Exemplo: organização oral: mordida, canibalismo: é a incorporação (fazer passar o outro por dentro) oral.

Merleau-Ponty mostra como passamos dos aparelhos (perceptivos) para o corpo como estrutura de conjunto, isto é, como abertura às coisas e aos outros. Trata-se de uma experiência de sentirse nelas e neles - indivisivos num mundo indivisivo. Desse modo, a sexualidade como corporeidade (isto é, sistema total) é tudo. O sexual é coextensivo ao homem não como uma causa única, mas como uma 
dimensão fora da qual nada resta. O Eros na consciência está relacionado com o inconsciente. Este Eros como lógica de uma vida encarnada, dialética que a si própria imprime novo impulso - qual é a sua relação com o espírito? A Consciência?

O problema do inconsciente é que ele é um saber inacessível, indistinto do consciente. Porém na metapsicologia não podem existir sentimentos inconscientes. Em contrapartida, a representação como quadro interno seria o inconsciente: por exemplo, o sentimento cujo objeto é inconsciente. É aqui que psicologia e a filosofia faltam a Freud: a representação como quadro interno está desacreditada e orientar-se por ela é conhecer mal a teoria do inconsciente. Hoje, ela orientar-se ia pelo ek-stase.

\subsection{O Corpo na filosofia existencial}

Por vezes, com alguma razão, a filosofia merleau-pontyana aprofunda elementos existenciais. Em primeiro lugar, a ideia da presença no meio do mundo é uma concepção existencial, na qual, existe uma relação entre o homem e o mundo. Do mesmo modo, o corpo relaciona-se com a consciência. Em segundo lugar, MerleauPonty afirma que o mundo humano - ou o mundo da vida - é um sistema aberto.

Ora, sabe-se que Sartre considera o corpo à medida tal qual Merleau-Ponty, isto é, relacionado com o ser, a consciência:

O Para-si deve ser todo inteiro corpo e todo inteiro consciência: não poderia ser unido a um corpo. Similarmente, o ser-para-outro é todo inteiro corpo; não há aqui fenômenos psíquicos a serem unidos a um corpo; nada há detrás do corpo. Mas o corpo é integralmente psíquico (SARTRE, 1998, p. 388). 
Como já vimos, é o entrelaçamento entre natureza e cultura como expressão simbólica que faz com que o corpo seja uma psique. A fenomenologia depende dessa homogeneização: a percepção levada à categoria das coisas, como são, só é possível na medida em que há uma "carne" compatível com a "carne" do mundo. Segundo Merleau-Ponty, a liberdade é condicionada, embora isso não queira dizer que a vida humana segue um determinismo absoluto, o que se nega é a liberdade absoluta sartriana. A liberdade humana é condicionada pelo mundo em que vive e pelo passado onde viveu. Não existe determinismo e nem escolha absoluta.

Ocorre um fato interessante: nós escolhemos nosso mundo e o mundo nos escolhe. Nosso ser é marcado por estruturas diversas: histórica, psicológica, biológica. Nossa existência é configurada por uma situação que tem seu fundamento em tais estruturas. A situação, porém, é sempre aberta: nossa liberdade nos insere em um mundo aberto. Os genes, por exemplo, possuem uma estrutura fixa, mas que também não possui cobertura. $\mathrm{O}$ mundo humano é um sistema que além de ser aberto é incompleto. A história marcada pela evolução e, por vezes, pelo progresso, é a prova magna da construção humana de sentido. O concreto do corpo é também controverso. Afinal, o que Merleau-Ponty avista é que há um corpo que tem uma mesma carne, um ponto de interseção no seio do mundo.

Embora considere a unidade corpo/consciência, Sartre identifica alguns problemas na nossa concepção existencial. O meu corpo é sempre um problema, pois, não o vejo no mundo, parece algo desconhecido:

Não nego, nem pretendo ser desprovido de cérebro, coração ou estômago. Mas, antes de tudo, importa 
escolher a ordem de nossos conhecimentos a partir das experiências que os médicos puderam fazer com meu corpo é partir da concepção de meu corpo no meio do mundo e tal como é para outro. Meu corpo tal como é para mim, não me aparece no meio do mundo (SARTRE, 1998, p. 385).

Na psicologia, a ordem mental aparece como algo para além do meu corpo, ou melhor, o corpo visto como um utensílio. Desse modo, o corpo é sempre do outro. Mas o meu corpo é meu próprio ser. É através dele que a existência manifesta sua facticidade, isto é, a contingência encarnada. Aprofundemos essa perspectiva de leitura.

\subsubsection{Corpo e Consciência: relação existencial}

O corpo existencial não possui um significado material. Essa afirmação é um ponto importante na argumentação sobre a relação corpo/consciência. Em uma estrutura neurocientífica, o corpo sempre terá uma conotação apenas empírica. Porém, a base material não explica completamente o grande fenômeno que é a consciência. A possibilidade extrapola qualquer condição material de informação. Numa perspectiva existencial, é a consciência a base de toda a estrutura ontológica do homem.

Sendo a consciência uma espécie de "natureza” humana, então, a ideia de corpo, para Sartre, só pode ter um sentido existencial no qual prevaleça a consciência e, por consequência, a liberdade. Trata-se aí de uma consciência encarnada que revela o mundo objetivo e subjetivo, embora, tais mundos sejam correlatos. Quer dizer: o sentido do mundo dos objetos já pressupõe um mundo de significado humano que careceu um dia de sentido e que foi iluminado por uma escolha livre da consciência. Ora, para Merleau-Ponty, a condição corporal do 
homem é uma situação que, de alguma forma, limita a liberdade ou coloca do lado do ato livre certo determinismo. Agora, no existencialismo sartriano, a consciência embora seja e esteja no mundo, é sempre purificada de toda imanência. Essa ideia pode nos conduzir para um discurso que coloca a consciência em detrimento do corpo. Sartre, no entanto, deixa claro que o corpo é o próprio Para-si, embora tenha seu sistema que o torna passível de episteme, mas, o corpo é uma experiência existencial, isto é, tudo o que somos liberdade, contingência - e nossos estados - náusea, tédio, angústia - é manifestado pelo corpo.

Desse modo, muitos estudiosos de Sartre afirmam uma filosofia da negatividade. Acontece que se trata de uma negatividade de forma original, isto é, na consciência; pois, é a estrutura da consciência que é negativa. Portanto, a expressão "negar o mundo" (totalidade destotalizada) não é correta, mas, esse negar é a revelação de uma escolha de ser que surge a partir de um significado. Como já dissemos, o mundo é vazio de significado, é através da consciência que o ser do mundo se revela. A consciência "deve ser livre em relação a toda realidade particular, e essa liberdade deve poder definir-se por um estar no mundo que é ao mesmo tempo constituição e nadificação do mundo" (SARTRE, 1998, p. 442). Nadificar é dar um significado diferente à coisa, tendo em vista que o "nada" está presente em toda parte. Sendo do mundo, pelo corpo, a consciência não pode negar o mundo, pois, negar o mundo significa negar a si mesmo.

Assim, se, para Merleau-Ponty, a liberdade de projetar-se se dá numa relação com o mundo, para Sartre, o mundo se faz nessa e por essa relação: "meu projeto último e inicial - pois constitui as duas coisas ao mesmo tempo - e sempre, como veremos, o esboço de uma 
solução do problema do ser. Esta solução, todavia, não é primeiro concebida e depois realizada. Somos esta solução, fazemo-la existir pelo nosso primeiro comprometimento, e, portanto, só podemos captá-la vivendo-a" (SARTRE, 1998, p. 570-571). O ser no mundo não é uma posição inerte, mas um problema. Temos, então, uma relação mundana de busca e criação que somos nós mesmos. Em tudo está em jogo o nosso próprio ser, isto é, o ser do mundo só faz sentido em face do nosso próprio ser. Nesse circuito, podemos, enfim, falar de negação, mas é uma negação do próprio ser e não do mundo, condição de surgimento do mundo: "o para-si é, por si mesmo relação com o mundo; negando-se como ser; faz com que haja um mundo, e, transcendendo esta negação rumo as suas próprias possibilidades, descobre os "istos" como coisas-utensílios" (SARTRE, 1998, p. 388).

Os istos revelam meu projeto de ser, doando sentido a esse mesmo isto e posteriormente ao mundo. Para a psicanálise existencial sartriana, essa tese é essencial, pois, todo ato, gesto e os istos são reveladores. Os istos que estão ao nosso redor são como uma espécie de corpos dilatados.

É a falta de ser do homem que estabelece a ordem do mundo, mas, o mundo também é contingente. Uma ordenação mundana $a$ priori significaria uma estrutura da natureza humana. Nesta questão, uma ideia de natureza, como pretendemos mostrar nesse estudo, fica comprometida. Mas, negar a natureza não é negar a ciência? Sobre essa questão voltaremos mais tarde. Já, de antemão, o que podemos considerar é que a própria relatividade da ciência moderna é ontológica, isto é, dá-se na medida em que o homem e o mundo são seres relativos de modo que o princípio de seu ser é a relação.

Se a relação é essencial, então, o ser aí significa também relação. 
A possibilidade de ser que se dá pela relação só é possível porque somos corporeidade. Não é possível ser sem um corpo; esse corpo não pode ser um utensílio, mas, o próprio ser. Caso contrário, cairíamos em um círculo quase gnóstico, uma consciência que não é um corpo e um corpo que é utensílio de utensílio.

A tese sobre a contingência é decisiva na argumentação da ontologia do corpo. Segundo Sartre, existem duas contingências:

Por um lado, com efeito, se é necessário que eu seja em forma de ser aí, é totalmente contingente que assim seja, porque não sou fundamento do meu ser; por outro lado, se é necessário que eu seja comprometido neste ou naquele ponto de vista, com exclusão de todos os outros. É esta dupla contingencia, encerrando uma necessidade, que denominamos facticidade do para-si (SARTRE, 1998, p. 391).

O corpo é a própria facticidade, é o ser para si. Esse enunciado é corroborado por Sartre, a partir dos seguintes argumentos: o primeiro argumento segue um princípio existencial: "existir e situar-se constituem a mesma coisa". Toda existência é situada a partir do tempo e do espaço. O segundo argumento fixa-se sobre a relação: "o corpo identifica-se com o mundo inteiro, enquanto esse é a situação do para-si e medida de sua existência". É a partir do corpo que a existência acontece. O corpo é, portanto, um modo de ser, "a forma contingente que a necessidade da minha contingência assume" (SARTRE, 1998, p. 392). É, pois, a fenomenologia da corporeidade que estabelece o princípio existencial do corpo, não a fisiologia. Isto significa que uma ontologia do corpo não é necessária para analisar as dimensões do corpo, porque não está em condição de se referir à minha experiência do meu próprio corpo. Noutros termos, essa 
experiência fenomenológica do corpo próprio possui uma mesma experiência da existência no mundo. $\mathrm{O}$ ser corpo não se distingue das situações do para-si, pois, a existência e a situação são uma mesma realidade. Não há nenhuma existência real que não seja situada, tal condição só é possível porque há um corpo. Também da mesma forma que o Para-si, o corpo é pura transcendência rumo ao ser. Neste sentido, a individualidade subsiste na dimensão do ser-para-si e não no corpo, como afirmara Platão; o corpo e a alma estão em uma mesma situação ontológica, na qual, somente um projeto de ser ou a consciência de si é capaz de ser um princípio individualizador.

É na sensibilidade corpórea, entretanto, que todas essas intuições sobre a ontologia do corpo são descritas. $\mathrm{O}$ ser corpo significa não possuir um sistema de orientação e coordenação, mas, ser esse sistema. O meu corpo, na sua facticidade, é experimentado por mim como portador dos meus cinco sentidos e, por conseguinte, como centro de orientação e de referência do meu campo perceptual. Tal campo perceptual, enquanto meu corpo, revela sempre o ponto de vista. Merleau-Ponty, por exemplo, sempre situara essa abordagem via a ideia de certo contexto de mundo. Esse mesmo corpo é também o ponto de partida das minhas possibilidades e decisões futuras. Novamente, como duplo centro, a ideia de corpo ultrapassa o seu predicado fisiológico, deixando de lado a estrutura comportamental do sistema mecânico. Nascimento, passado, contingência, necessidade de um ponto de vista fazem parte do corpo, como ponto de partida, isto é, como condição de possibilidade da ação do ser no mundo.

Ao mesmo tempo, a experiência consciente desse corpo é imediata. Isso quer dizer que o corpo é uma estrutura ontológica, não um mero instrumento usado pela consciência. Desse modo, 
consciência e corpo formam uma estrutura única, psicofísica. Sou o corpo dor, o corpo prazer, o corpo sobre um objeto, o corpo dor nos olhos. Sintetizando, podemos afirmar que é o corpo como para-si, na qual temos uma consciência totalmente identificada com a corporeidade. Essa teoria corpórea pode ser sintetizada com a seguinte premissa: "o corpo como ser para si é o corpo que sou, o corpo concreto". Neste plano, não ocorre qualquer distância entre o corpo e a consciência.

Essa estrutura que surge na ideia de uma consciência imediata tem como base o conceito de sentido como orientação, que é uma estrutura constitutiva da coisa. Todo objeto aparece sobre fundo de mundo e se objetiva como forma entre objetos. Para Sartre, não há uma sensação subjetiva, mas é a coisa que se manifesta à consciência. Desse modo, o sentido é eleito perante a consciência em que irá se doar. É dado, pois, se opera a partir da distribuição original das coisas e objetiva a facticidade mesma própria do meu surgimento. Sartre também afirma que o meu corpo está em toda parte do mundo como ser-para-si na medida dos sentidos, como já dissemos anteriormente, é o ser em meio ao mundo através do corpo. O ser-para-si é predicado como falta, portanto, o corpo é ação, não só sentido. Existe uma relação original entre corpo e mundo, a consciência se objetiva diante do mundo posteriormente a essa relação original. Sendo falta, o ser corpo é uma ação intencional do futuro, na qual o meu corpo parte de uma situação presente e age em vista de um futuro.

Assim ao término dessas exposições, sensação e ação estão reunidas e constituem uma unidade. Renunciamos à ideia de nos dotar primeiro de um corpo para estudar depois a maneira como captamos ou modificamos o mundo através dele. Ao contrário, 
estabelecemos como fundamento da revelação do corpo como tal a nossa relação originária com o mundo, ou seja, nosso próprio surgimento no meio do ser (SARTRE, 1998, p. 411).

Aos olhos de Sartre, o corpo possui uma realidade ontológica, na medida em que ele é também pura contingência e facticidade. Por isso, o corpo é pura transcendência: é na transcendência que a realidade do mundo aparece, pois o corpo precisa ser no mundo. A consciência imediata do corpo além de contingente é dessacralizada: o conceito é caro, para Sartre, pois, o corpo, faz parte de uma estrutura ontológica existencial, na qual o complexo utensílio do mundo se faz na busca pelo ser. Ora, todo esse processo faz parte da estrutura psicofísica aonde vimos que o corpo é uma realidade ontológica. Neste caso, temos uma primeira relação entre o corpo e a consciência. Portanto, o corpo é ser-para-si, enquanto em-si superado pela realidade da consciência. Essa teoria existencial nos revela que a relação corpoconsciência é contingente; entretanto, na realidade humana, possui uma unidade substancial, na qual sem a consciência o corpo seria um objeto inerte, ou seja, um em-si opaco.

Cabe observar, em termos sartrianos, que existe o corpo abstrato, onde a consciência se distancia do corpo, formando conceitos que extrapolam o ser-para-si e a corporeidade. No caso do corpo concreto, a consciência possui de maneira imediata um corpo, isto é, o corpo como estrutura consciente da minha consciência. Aqui temos uma consciência que é irrefletida, já o corpo abstrato surge de uma consciência reflexiva. Vimos, anteriormente, que a dor faz parte do ser que a sente, pois, neste caso, a consciência é imediata, ou seja, está unida ao corpo. Por outra parte, a reflexão sobre a dor e posteriormente sobre o mal acontece a partir de um fundamento que 
reflita sobre a dor, mas essa reflexão acontece após a estrutura mundana que originou essa dor. Como descreve Sartre (1998, p. 422):

Mas, eis que deixo de ler, de repente, e agora fico absorto na captação de minha dor. Significa que dirijo sobre minha consciência presente, ou consciência visão, uma consciência reflexiva. Assim, a textura atual de minha consciência refletida - em particular, minha dor - é apreendida e posicionada por minha consciência reflexiva.

Aqui o conceito sartriano de reflexão ganha importância no contexto existencial da dor:

É uma captação totalitária e sem ponto de vista, um conhecimento extravasado por si mesmo e que tende a objetivar-se, a projetar o conhecido à distância para poder contemplá-lo e pensa-lo (SARTRE, 1998, p. 422).

Vejamos que a reflexão quer tornar a dor algo psíquico, um objeto; posteriormente essa dor é personificada através do conceito de mal. Temos aqui uma ideia importante dentro da psicanálise existencial de Sartre e da psicanalise em geral, pois, o mal, em si mesmo, possui um animismo. Na religião esse animismo do mal é mais complexo e, portanto, um ponto essencial dentro da fundamentação religiosa. Em Merleau-Ponty, vimos também que a natureza foi sendo mistificada através do ato reflexivo. No nosso caso, é possível até mesmo perceber o mal de forma psíquica que ultrapassa os limites da corporeidade, da natureza e do próprio ser. Apresentando o conceito de corpo, numa leitura existencial, poderemos compreender a corporeidade a partir de um ponto de vista finito, contingente e concreto. Esses princípios existenciais são a forma pura do corpo, enquanto natureza. Para Merleau-Ponty, o corpo é o 
elo entre a natureza e a cultura. Entretanto, a estrutura psico-física traz o corpo como natureza que cria a partir do criado, da natureza enquanto o além do homem, determinando um espaço psico-físico. $\mathrm{O}$ referido filósofo pensa essa relação corpo - psique como que desvelada pela própria linguagem libidinal: aos poucos a cultura vai ultrapassando os limites da natureza e do corpo.

Já, segundo Sartre, a consciência nunca deixa de ter o seu corpo. Existe uma relação existencial que corresponde com a interpelação do Dasein, na qual os sentimentos existenciais tais como o tédio, a náusea, a angústia e o niilismo surgem da relação corpo - consciência - mundo. Daí ocorre que sentimos a existência de fato, através de uma consciência que deixa de ser reflexiva e passa ao ponto imediato do ser-para-si. Afinal, o estudo da natureza como corpo e lógos nos faz pensá-la como uma estrutura contingente que pertence ao complexoutensílio do homem. A natureza é o próprio homem na sua estrutura psico-física, mas a natureza é um irredutível que só pode ser conhecida a partir de uma relação existencial. Desse modo, consideramos que a ciência tem uma relação com a natureza que nunca será completa na medida em que o mundo e o homem são correlatos. Ora, essa correlação tem uma conotação puramente existencial, na qual, a ciência revela o ser cientista na sua relação com a natureza. Em tal caso, o conceito de Deus, esboçado no início dessa pesquisa como uma estrutura necessária na articulação da ideia de natureza, surge também como um paralogismo que nasce de uma reflexão da consciência, da mesma maneira que o mal.

\section{Conclusão}

O caminho para uma possível reflexão sobre a ideia de natureza 
foi por nós apresentada a partir do corpo humano. Nessa retrospectiva, dois pensadores contemporâneos tornaram-se decisivos nessa pesquisa: Merleau-Ponty e Jean-Paul Sartre. Inicialmente, apresentamos a ideia de natureza vista pelo primeiro filósofo a partir da história da filosofia. Percebemos então que a falta de um método eficaz para o estudo sobre a natureza, fez com que o pensamento antropocêntrico se tornasse a matriz cognitiva para o estudo da natureza.

Ao mesmo tempo, nossa pesquisa procurou mostrar que o método fenomenológico utilizado por Merleau-Ponty e Sartre era viável para descrever uma ideia da natureza, tal qual se apresenta ao pensamento, a partir de elementos existenciais concretos. Desse modo, a fenomenologia é importante, pois trata dos aparecimentos. A questão do aparecimento é um grande problema filosófico que foi deixado para trás pelas principais correntes idealistas e racionalistas. Ademais, a assim denominada pós-modernidade, através da filosofia ocidental relevou a fenomenologia que tem como princípio "voltar às coisas mesmas".

O corpo analisado pelo idealismo tem, como pano de fundo, o conceito de instrumentalidade, pela qual, o corpo seria um instrumento existindo pela forma e utilizado pela razão ou pela alma. Sem mais, a ideia da natureza acompanha esse idealismo, fazendo uma metafísica da natureza, conforme a estrutura da mente.

Isso nos leva a reconhecer, pois, que o corpo humano é relevante para a formulação de uma ideia da natureza. Merleau-Ponty coloca o corpo como não mais animalidade, mas como uma transição proveniente da evolução biológica. Em função disso, percebe-se que, para explorar a ideia da natureza, não se pode formular uma ideia 
objetiva sobre ela, já que a natureza, em sua forma própria, possui uma estrutura externa que não se homogeneíza com nenhuma doutrina humanística buscando depurá-la de forma total. Todavia, o corpo é o ponto de surgimento do homem na natureza. Há uma linha ontológica da natureza que surge com a ontologia do corpo e também do próprio homem a partir de sua existência. Para Husserl, existe aqui um Ineinander, isto é, a inerência de si ao mundo ou do mundo a si, de si ao outro e do outro a si. Noutras palavras: o homem a partir da corporeidade e também da consciência - estrutura psico-física - que tem sobre si o outro e o mundo, juntamente a animalidade e a humanidade. É esse entrelaçamento exposto no título do trabalho aqui realizado sob a construção da ideia de natureza, como corpo e lógos que está em questão. A corporeidade, antes da razão, é um recipiente do mundo, da natureza. A percepção se encontra, pois como que implicada por nosso corpo. Neste sentido o eros é visto pela psicanálise como uma posse do outro e pelo outro de maneira que o lógos é introduzido pela fala.

Na mesma direção de Merleau-Ponty, Sartre aponta uma teoria sobre o corpo sem pretender esboçar uma ideia da natureza. Trata-se, para o autor de O Ser e o Nada, de pensar o corpo como ser-para-si ou consciência concreta de si. Tal princípio é pontual na investigação proposta nesta pesquisa, ou seja, tentamos a partir da corporeidade sartriana encontrar, como em Merleau-Ponty, uma ideia da natureza. A ideia de que a consciência não deixa de ter um corpo é o ponto central da tese de Sartre sobre o corpo, enquanto contingência, facticidade, relação, posição e ação. Percebe-se que os predicados corporais são também da consciência e, portanto, do próprio ser-parasi. Neste sentido, o corpo não representa, para Sartre, uma estrutura inerte, incapaz de criação sobre o mundo; ele não "prende" o homem 
no mundo, mas, é também causa e motivo de transcendência. Sob essa ótica, uma ideia de natureza, a partir do corpo na perspectiva existencial, só pode exprimir uma natureza do em-si, sendo pensada pelo para-si, que se relaciona com a natureza pelo corpo que é também consciência. Essa ideia contrasta, sem dúvida, com a teoria merleau-pontyana que advoga uma relação de mistura entre o ser e o nada, o homem e o mundo. Para Merleau-Ponty, embora considere também a estrutura psico-física, o corpo é quem abre o caminho do ser. Trata-se de superar os impasses das filosofias da consciência.

Para os dois autores, o corpo não é uma coisa, um objeto, mas é o próprio ser, sensação e abertura para o mundo. Essa relação que o corpo estabelece com o mundo cria a possibilidade de uma fenomenologia da percepção, na qual, os objetos sentidos pelo corpo tornam-se uma extensão da corporeidade. Devemos entender a natureza a partir da fenomenologia existencial, considerando-a como uma estrutura correlata ao corpo e que se torna um complexo de utensílio pela consciência que cria o mundo da vida.

\section{Referências Bibliográficas}

MERLEAU-PONTY, Maurice. A natureza. São Paulo: Martins Fontes, 2000.

SARTRE, Jean-Paul. O ser e o nada. Petrópolis, RJ: Vozes, 1998.

SOKOLOWSKI, Robert. Introdução à fenomenologia. São Paulo: Loyola, 2010. 